\title{
1. The evolving interactions between adaptation research, international policy and development practice \\ Ian Noble
}

\section{INTRODUCTION}

The role of this chapter is to explore the origins of climate change adaptation as a research discipline and as an emerging issue for public policy. It also explores the linkages between adaptation policies and development policy and practice. This is a scene-setting chapter for the more detailed and erudite analyses that follow. To cover such a remit within the constraints of a readable chapter would always be a challenge. Hence, I admit that this is a personal view, probably contentious in places, but it draws upon a fortunate experience of working among the best research communities for several decades, followed by the personally transformative experience of moving to a decade of attempting to design and deliver adaptation within a development agency.

Aspects of the origins of adaptation efforts have already been extensively reviewed and I draw upon the work of these earlier scholars. These include Bodansky's (1993) analysis of the early negotiations; Burton et al.'s (2002) overview of adaptation at that time; Orlove's (2009) broad review of the development of the concept of adaptation; Schipper's (2006) history of adaptation in the negotiations; IISD's summary of more recent negotiations (Allan et al. 2017); and Bours et al.'s (2014) analysis of frameworks for the monitoring and evaluation of resilience and adaptation.

The chapter follows a time line of the entwined development of adaptation within the broad categories of: (1) scholarship (that is, the peer-reviewed literature including the Intergovernmental Panel on Climate Change, IPCC); (2) international policy formulation centred on the negotiations around the United Nations Framework Convention on Climate Change (UNFCCC) Conference of the Parties (CoP) process; and (3) development practice. The last of these is based mostly on the rise of adaptation considerations into the actions of the World Bank, as I am most familiar with its work and the large 'grey literature' that is often unfamiliar to many engaged in adaptation scholarship. The World Bank is a large multilateral development agency with a diverse range of technical 
skills and funding mechanisms. But it is also limited, in that it deals firstly with sovereign governments and then only indirectly with other players, both governmental and non-governmental, which are responsible for so much of the on-the-ground implementation. From the above, it is clear that this chapter also emphasizes adaptation practice as it is relevant to developing countries, where the challenges faced and the effort put into adaptation practice are the most pressing and varied. Table 1.1 seeks to summarize the following sections of this chapter and some of the key elements of the entwined timelines.

\section{EARLY SCHOLARSHIP}

Without trying to trace the concept of adaptation back to the Ancient Greeks and via Darwin (Orlove 2009), the idea of the inevitability of a need to adapt to a changing climate is almost as old as the concept of climate change itself. Even Arrhenius, one of the first to describe the core processes of climate change and their likely effect on temperatures, had a view. He saw that continued emissions of carbon dioxide $\left(\mathrm{CO}_{2}\right)$ would mean that we would be living in a different environment, but he hoped for benefits:

By the influence of the increasing percentage of carbonic acid in the atmosphere,
we may hope to enjoy ages with more equable and better climates, especially
as regards the colder regions of the earth, ages when the earth will bring forth
much more abundant crops than at present, for the benefit of rapidly propagat-
ing mankind. (Arrhenius 1908)

In the early twentieth century a small number of scientists continued to elaborate the physics and chemistry of the 'greenhouse'1 effect. By the 1950s and 1960s several major steps were made as the confirmatory evidence that the human contribution to the greenhouse effect could affect the Earth's climate on a scale at least as important as the Earth's orbital variations. Among the most important steps were the first attempts at computer modelling the phenomenon (Phillips 1956; Plass 1956; Manabe and Wetherald 1967), and Keeling's (1960) start to regular monitoring of $\mathrm{CO}_{2}$ at Mauna Loa in 1958, initiating an era of cooperative work using modelling, palaeo-records and observation. As the modern discourse on climate change developed in the 1950s and 1960s, the focus was, of necessity, on demonstrating the validity of the greenhouse effect.

Little was written about the impacts of climate change on biological and human systems, but it was usually assumed that these systems could cope with a changing climate through the processes of adjustment and 


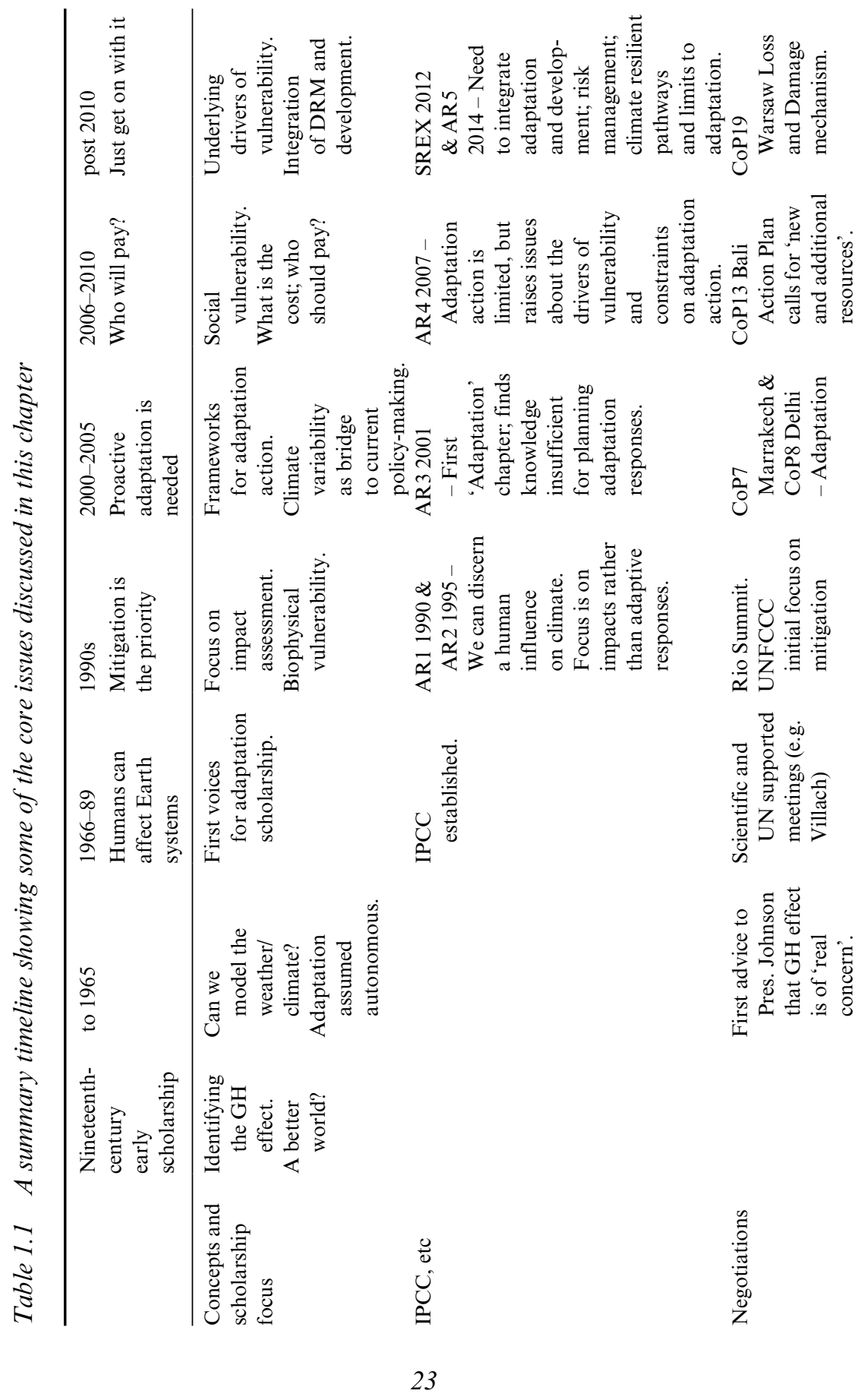




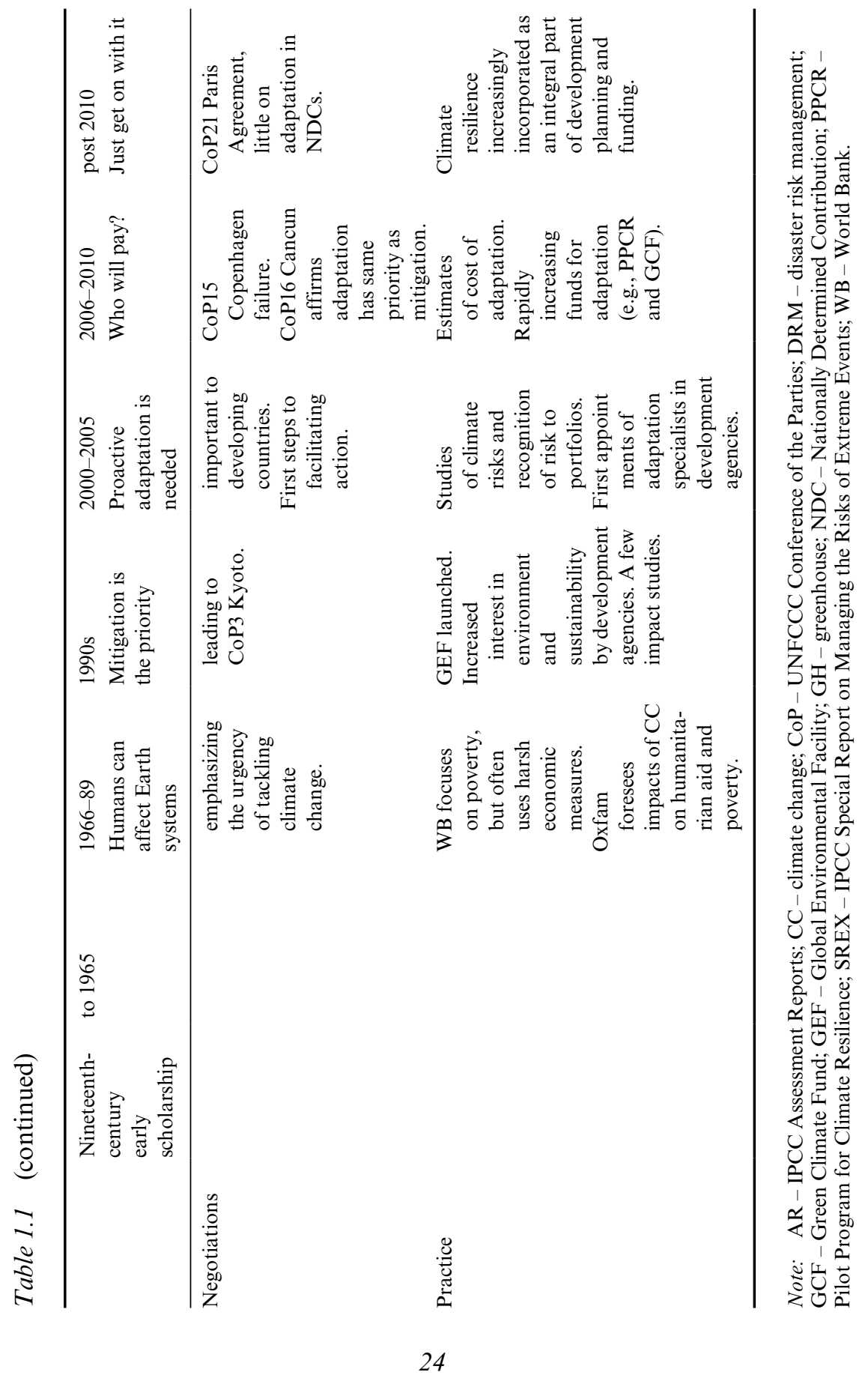


adaptation exhibited in the past (often called autonomous adaptation). Kates (2000) and Schipper (2006) have described three schools of thought about the role of adaptation in responding to climate change: the 'adaptationist' view, as above, where no explicit adaptation action is required as the invisible hand of either natural selection or market forces will ensure that ecosystems and societies will adjust to the changes; the 'limitationist' view, where with sufficient effort in mitigation the major impacts of climate change can be avoided; and the 'realist' view, where adaptation is considered a crucial and realistic response option, along with mitigation.

\section{5-1990: REALIZATION THAT HUMANS CAN ALTER EARTH SYSTEMS}

During the 1960s the study of ecology began to focus on a more systemsbased and quantitative understanding, and in 1968 publications by Hardin ('The tragedy of the commons') and Ehrlich (The Population Bomb) promoted the wider community to think about the capacity of the Earth's biological and human systems to cope with sudden change. Although the two publications did not deal with climate change they prompted thinking about how Earth's biological and social systems behave and interact and what impact climate change might have over the rest of the century or longer.

During this period there was little political or development focus on climate-related matters. It was a period of post-war optimism focusing on growth, overshadowed by the Cold War. But as early as 1965 President Johnson's Science Advisory Committee warned that the greenhouse effect was a matter of 'real concern', and even discussed possible geo-engineering responses (PSAC 1965).

The 1970s represented the next phase in climate change and adaptation discourse, mostly triggered by the First UN Environment Conference in Stockholm in 1972, which was to provide guidelines for governments and organizations faced with multiple environmental problems. Its final declaration outlined 26 principles mostly concerned with the maintenance of renewable resources and the non-depletion of non-renewable resources. They recognized the particular difficulties facing developing countries and concluded that more rapid development would help reduce environmental damage. But another principle stated that environmental policies should not be allowed to hamper development. The only mention of climate change was a recommendation (number 70 out of 109) to evaluate the likelihood and magnitude of climate effects from pollution and to disseminate these findings before embarking on those polluting activities (UN 1972). 
The decade following Stockholm was a period of increasing neoliberal economic policies and economic globalization focusing on economic growth. But at the same time there was increasing recognition of growing environmental threats, including climate change. During the 1970s the World Bank, recognizing the plight of developing countries, announced a focus on reducing poverty in developing countries, but this was largely based on macroeconomic measures such as 'structural adjustment' and related controversial policies (e.g., Washington Consensus; Gore 2000; World Bank 2005). But other agencies involved in poverty relief and development were sensing the threat of climate change to their objectives. For example, Oxfam (1983) reported on the increase in extreme weather events and their impact on poverty, which led eventually to its global strategy for dealing with the threats of climate change (Oxfam 2000).

During the 1970s scholarship was well ahead in thinking on climate change and adaptation. The first paper in the journal Science with a strong focus on climate change and the need to adapt was published in 1970 (Landsberg 1970). In 1977 the journal Climatic Change was launched. In the first issue, three out of seven papers dealt with impact and adaptation themes. One paper (Glantz 1977), which outlined nine fallacies undermining effective responses to the drought in the Sahel, recognized the relevance of lessons learned from development experience to designing adaptation responses.

During the 1970s and 1980s scientists gradually developed a better understanding of the greenhouse effect, how it interacted with the carbon cycle and what impact climate change might have on natural and human systems. A UN-sponsored meeting in Villach (in 1985) concluded that climate change must be considered a 'plausible and serious probability', and that the use of past climate data as a guide to the future was no longer valid. This eventually led the United Nations Environment Programme (UNEP) and the World Meteorological Organization (WMO) to establish the IPCC in 1988, with its first assessment report in 1990 (see Oppenheimer 2007 for more details). IPCC AR1 (WG III) ${ }^{2}$ identified themes that still underlie our approach to adaptation. These include that mitigation and adaptation are complementary and must be considered as an integrated package, and that adaptation planning must be comprehensive and integrated with other planning processes including disaster preparedness. It also included an outline of a 'Framework Convention on Climate Change' that formed the basis of the 1992 UNFCCC. This same group of scientists were also largely responsible for the establishment of the International Geosphere-Biosphere Programme (IGBP) in 1986, an open, collaborative research programme to investigate global change (Seitzinger et al. 
2015). The IGBP work ranged from climate modelling to the analysis of potential impacts of these changes and the options to manage them. Efforts to engage more closely with social scientists in this research were largely unsuccessful, leaving the research with a strong biophysical focus (Morais 2015). An equivalent organization focusing on the social sciences (the International Human Dimensions Programme on Global Environmental Change, IHDP) was not set up until 1996, and cooperation between the two organizations was always subject to the two-culture syndrome. This syndrome is still being tackled in Future Earth, the successor to both organizations (Future Earth 2013).

In 1983 the UN requested the Brundtland Commission to investigate the conflict between rapid development and environmental problems. This led to the report Our Common Future (UN 1987), which united environment and development within the concept of sustainable development. The report noted the conclusion from the Villach (1985) meeting and warned that if '[mitigation] policies cannot be implemented rapidly, governments should develop contingency strategies and plans for adaptation to climatic change' (UN 1987).

Some countries were also anticipating the need to deal with climate change in both national and international policy formulation. In 1986 the United States (US) Senate requested two studies: the first on the 'health and environmental effects of climate change', and the second on the 'policy options to stabilize atmospheric greenhouse gas levels'. This led to an Environmental Protection Agency (EPA) report on 'The potential effects of global climate change on the United States' (Smith and Tirpak 1989), which largely followed the request to focus on effects and only briefly commented on adaptation responses.

By the end of the 1980s, while there were no formal frameworks for dealing with adaptation to climate change, there was recognition that climate change was a future threat and that adaptation was very likely needed to maintain sustainable development. The IPCC AR1, besides providing an outline for what was to become the UNFCCC, also raised many of the concepts that are elements of existing frameworks; albeit often with different terminology. For example, the difference between what is now called autonomous and anticipatory adaptation actions appears throughout the discussion. In the coastal management section the authors use the broad categorization of response options as retreat, accommodate or protect. In dealing with resource management more generally, their categorization of approaches includes knowledge and technology generation and transfer, no-regrets actions, and the possible need for what would now be called transformative adaptation actions. They also discussed the limits and barriers to adaptation (IPCC AR1, WGIII 1990). 


\section{0s: MITIGATION AS THE PRIORITY}

During the late 1980s a series of scientific and governmental meetings were held in the lead-up to a UN Conference on Environment and Development, or UNCED (see Bodansky 1993 for a detailed description). The release of the IPCC AR1 (1990) gave an authorative scientific statement that climate change was a global problem and one that would need to be tackled soon via the engagement of all countries, developed and developing. One of the three major conventions agreed in Rio de Janeiro was the UNFCCC. Its Article 2 lays out its core objective, namely:

the stabilization of greenhouse gas concentrations in the atmosphere at a level that would prevent dangerous anthropogenic interference with the climate system (UNFCCC 1992). Such a level should be achieved within a time-frame sufficient to allow ecosystems to adapt naturally to climate change, to ensure that food production is not threatened and to enable economic development to proceed in a sustainable manner.

Greenhouse gases (GHGs) were seen primarily as pollutants to be managed by a process of emissions reduction at a rate estimated to be environmentally and socially tolerable (see also Keskitalo and Preston, the Introduction to this volume).

The developing countries were concerned about the additional costs of impacts of climate change, but simply did not have the negotiating power to keep adaptation issues at the forefront (Bodansky 1993). The compromise outcome was the objective in Article 2 that emissions reduction should occur at a rate that allowed 'ecosystems to adapt naturally' and not to threaten development. The developed countries agreed to fund developing countries' 'full incremental costs' of abatement (mitigation) actions, but for adaptation more vague terminology was used by referring to 'assistance' in 'meeting costs of adaptation'; a more generic term than 'meeting the costs'.

As the engagement of developing countries in the negotiations increased it became clear that they did not treat the challenge as purely environmental, but also as a development issue. They demanded the 'environmental space' (that is, the right to emit) for their own development. In particular, the Alliance of Small Island States (AOSIS), seeing that they were most at risk from the impacts of climate change, placed pressure on developed countries to raise their mitigation ambitions and demanded more substantial support for adaptation.

In the terminology of Kates (2000) and Schipper (2006), this was an apparent retreat from the more 'realist' approach that had gained support during the 1980 s to a more 'limitationist' approach. A number of factors 
contributed to this shift. As international action built towards the Rio de Janeiro 1992 conference, concern about the magnitude of the climate change problem increased, and also concern about the uncertainty surrounding it. Understanding of the mechanisms for achieving mitigation and estimates of the costs were still poor (Bodansky 1993), but adaptation was even less understood. The scientific literature contained both dire warnings of the impacts of climate change and optimistic opinions that both ecosystems and social systems could adjust rapidly enough to avoid major damage. It was clear that action on mitigation was essential, so this became the focus of the UNFCCC.

In the pressure of negotiations, some also considered that a discussion of adaptation was an implicit admission that mitigation efforts might fail, or that adaptation might for some countries provide a potential disincentive, or pretext for inaction, in pursuing mitigation (Burton 1996). Adaptation was also regarded as too ill-defined to be incorporated effectively into a negotiated, legally binding text. It also raised concerns about the scale of resources needed to assist developing countries, and of accountability and liability for climate impacts. Many preferred to assume that adaptation would largely take care of itself through autonomous actions both in nature and in societies. Those wanting to promote discussion of the need to adapt were usually stymied by demands for better (mostly biophysical) impact analyses, and the question: 'Adapt to what?' (Bodansky 1993; Schipper 2006).

These attitudes continued to dominate the first Conference of the Parties to the UNFCCC (CoP1) in Berlin in 1995, and the preparations for the Kyoto Protocol in 1997 (UN 1998; Burton 1996). But at the same time research outputs could be seen as supporting this view. For example Darwin et al. (1995), based on studies of US farming systems, concluded that 'because of the ability of farmers to adapt, however, these changes are not likely to imperil world food production'. Initial global modelling studies supported this by concluding there would be little impact on global food production (Rosenzweig and Parry 1994). The first US National Climate Assessment in 2000, while recognizing that there would be significant regional and sectoral differences, concluded: '[ $\mathrm{f}]$ or the nation as a whole, direct economic impacts are likely to be modest' (USA National Assessment Synthesis Team 2000).

Smith et al. (1996), in summarizing a meeting on 'Adapting to Climate Change: An International Perspective', placed emphasis on autonomous adaptation, stating that, 'some adaptation will occur without any special intervention by human institutions. Ecosystems will naturally adapt... Human activities will adjust to climate change.' The emphasis was still on adjusting the rate of climate change to allow autonomous adaptation to 
occur, but admitting that 'additional intervention may be necessary'. In that case adaptation strategies would need to be identified and priorities determined. But, '[t]he most successful adaptation strategies are likely to be those that have other economic benefits'; a statement of the 'win-win' concept which, with the similar 'no-regrets' or 'low-regrets' concepts, dominated much of the discussion of adaptation.

The subsidiary role of adaptation in both scholarship and the negotiations persisted for a decade or more (Pielke 1998; Schipper 2006). Unlike the first IPCC report, the IPCC AR2 (1995) had little impact on the adaptation discourse. In fact, Kates (1997) described the AR2 WGII title (Impacts, Mitigation and Adaptation to climate change) as a misnomer, as despite describing impacts as potentially large, less than 5 per cent of the text dealt with adaptation responses.

The IPCC Assessments AR1 (1990) to AR3 (2001) included adaptation mainly as a brief add-on to chapters that sought to identify the impacts that might flow from various scenarios of climate and social change. The first specific chapter on adaptation appeared in AR3 (2001) and there were two in AR4 (2007). In AR5 (2014), four chapters specifically on adaptation and a broader set of chapters that embraced social issues were also included, but each was constrained within a negotiated, prescribed outline, which did not encourage a comprehensive interdisciplinary discussion of what is needed to achieve the actions necessary to progress adaptation, such as the scope of this Handbook.

But despite the secondary role for adaptation in the negotiations, researchers were advancing adaptation knowledge. The IPCC produced a Special Report on Technical Guidelines for Assessing Climate Change Impacts and Adaptations (Carter et al. 1994) that described a framework for the evaluation of adaptation strategies. Adaptation frameworks are discussed in more detail below, but the Carter et al. (1994) framework contains almost all of the elements of the multitude of frameworks that were to follow. But it is important to note that the framework follows a science-driven approach. It assumed that scientific analysis of mostly biophysical hazards should lead to recommended adaptation measures, with the additional implicit assumption that they will be taken up and implemented. It was still a research-driven point of view, concluding: 'Thus, communication between policy makers and researchers is essential, the former demanding of the latter solutions to problems and the latter informing the former of issues of importance and requesting the resources to research them.'

With the negotiation of the UNFCCC (1992) and the Kyoto Protocol (UN 1998), along with release of IPCC AR2 (1995), the mitigation community, both scholars and practitioners, had to move from making the 
case for action on climate change to examining context-specific options needed to inform practice. By the mid-1990s specialist journals that included a focus on adaptation were also starting to appear. However, the adaptation community still had to make the case for immediate, proactive action while attempting to lay the groundwork for more explicit advice that most anticipated would soon be needed.

Many adaptation specialists took up the approach of dealing better with current climate variability as a step towards coping with changing climates (Burton 1997). This led to frequent reference to 'no-regret' strategies (that is, actions that will be beneficial under current climates, largely irrespective of future climates) and 'win-win' options. ${ }^{3}$ Practitioners quickly adopted these terms, as they largely avoided the need to defend specific climate change impact scenarios. They also meant that many projects could be labelled as adaptation-relevant, even though their design did not consider climate change. This became an important ploy as special incentives and funds for adaptation started to become available.

\section{Development Agencies Awake to the Need to Adapt}

At this time both governments and development agencies were beginning to formalize climate change policies within their operations. For example, in 1997 the United Kingdom (UK) Government set up the UK Climate Impacts Programme (UKCIP) 'to co-ordinate climate impact research and to involve stakeholders in that research, with a focus on natural resources (water, agriculture, biodiversity)'. UKCIP originally embodied the assumption that as climate impact information was made available there would be a natural progression to action (UKCIP 2011), but quickly recognized the need to work closely with local governments which bore the brunt of climate impacts and adaptation responses.

During the 1990s development agencies began to incorporate climate change into their agendas, but in most cases they followed the example of the negotiations by focusing on mitigation. By the end of the 1990s the World Bank had established its Prototype Carbon Fund as a facility to raise public and private sector funding for mitigation projects in developing countries, building on the Clean Development Mechanism. But the World Bank did not have an explicit adaptation programme.

In the late 1990s the World Bank initiated several projects relating to climate impacts on water supply in the Andes and coastal protection in the Caribbean (Vergara 2005). These were essentially scientific impact studies driven by technical experts in the Bank with external funding. There were still barriers to accessing international funds to support adaptation. Initially it was difficult to access Global Environment Facility 
(GEF) funding for adaptation, as GEF was to focus on activities with global environmental benefits, and adaptation, unlike mitigation, was still regarded as having primarily local benefits. The strengthening of the World Bank operating principle that priorities should be country-determined sometimes hindered those who sought to promote greater effort in adaptation. In a 1999 forum on Ecologically and Socially Sustainable Development with senior staff from World Bank and European agencies, Robert Watson 'noted that the Bank is expected to respond to clients' demands, which are usually focused on short-term issues, as opposed to long-term issues such as global biodiversity and climate change, which are lower on most clients' development priorities' (World Bank 2005).

In 1999 Burton and van Aalst were asked to review the vulnerability of World Bank projects to climate change and the impact of projects on recipient countries' vulnerability. They found that climate risks were rarely mentioned in the project planning documents, even in areas with high current climate risks such as floods and cyclones. But in the implementation progress reports for those same projects climate risks were sometimes mentioned as a factor threatening, or having already impeded, project outcomes. They recommended that no case could be made for 'stand-alone' projects on adaptation, and that all investments should be designed as incremental additions to projects already justified for development purposes.

So as the decade, and millennium, drew to a close, there was general agreement among scholars that proactive adaptation would be necessary, and that a pathway to greater action was via a focus on climate variability and no-regret options. Most development agencies had recognized the risk to their portfolio, even though the risk was ill-defined and serious moves to bring climate risks into their operations were limited (see Klein et al. 2007 for an analysis of a wider range of agencies but with similar conclusions). Meanwhile the negotiations were still primarily focused on mitigation, with the Kyoto Protocol being so recent. There was also a strong international focus on the Millennium Development Goals that drew attention to the wider range of problems facing the globe.

\section{0-2005: PROACTIVE ADAPTATION ACTION IS NEEDED}

\section{Who Will Do the Heavy Lifting?}

In 2001 the IPCC AR3 reports were released and they attributed most of the warming of the past 50 years as likely ( $>66$ per cent) to be linked to human activities. In the first chapter specifically on adaptation in an IPCC 
report, the authors made it clear that some adaptation would be inevitable. They still focused on the importance of autonomous adaptation, but with the need to support this with proactive actions. They also emphasized that the knowledge of adaptation approaches and of how to improve adaptive capacity was insufficient for planning and rigorous evaluation of adaptation activities. This message was useful in that it clearly placed proactive adaptation, and support (read, 'funding') for it, on the global agenda. Burton et al. (2002) reinforced these messages by providing an alternative framework for adaptation research to the then dominant climate change projections, impacts and vulnerability approach, by focusing instead on the ways that bringing climate variability and change into existing policy and development practice could serve to reduce vulnerability.

Meanwhile, developed countries and development agencies were getting on with their own adaptation actions despite 'insufficient' knowledge. Many adaptation actions were still essentially knowledge-building, such as the first USA National Assessment (USA National Assessment Synthesis Team 2000). But UKCIP, a UK boundary organization, prepared a unified Risk, Uncertainty and Decision Making Framework (Willows and Connell 2003) linking climate change with the management of other risks and local development priorities, and was working with cities and other local governments to implement actions on the ground.

In the negotiations, pressure from developing countries had been building in the years following the mitigation focus of the Kyoto CoP3 in 1997. At CoP7 in Marrakech (2001) negotiators agreed to the first formal commitment to financially support adaptation activities. They also recognized the relationship between climate impacts and development by agreeing to support least-developed countries (LDCs) to prepare National Adaptation Plans of Action (NAPAs) to identify their urgent adaptation needs, and two funds were set up under the GEF to support adaptation projects (the Least Developed Country Fund to support the implementation of NAPAs, and the Special Climate Change Fund for a wider range of adaptation projects). The following year CoP8 was the first to be hosted, and thus chaired, by a developing country in Delhi. Although there were few substantive decisions on adaptation, the Delhi Declaration was agreed. It recognized that adaptation to the adverse effects of climate change was of high priority for developing countries and deserved urgent attention and action on the part of the international community. Meanwhile some organizations and scholars were debating the merits of a separate Adaptation Protocol under the UNFCCC (see Schipper 2006).

At CoP 11 in 2005 a distinct adaptation work programme, the Nairobi Work Programme, was established to share knowledge and lessons learned. It has served as a meeting place between adaptation practitioners 


\section{Research handbook on climate change adaptation policy}

and some of the scholarly community but its most valuable contribution has been in fostering collaboration between adaptation practitioners, be they governments, academia, multilateral or bilateral organizations, or non-governmental organizations (NGOs). It is an effective South-South and North-South collaboration venue. Unfortunately, many of its most valuable contributions remain deep in the grey literature, or unreported.

\section{The Proliferation of Adaptation Frameworks}

A major collaboration between leading adaptation scholars and development agencies led to the Adaptation Policy Framework for Climate Change to help guide the use of the growing funds for adaptation (Lim and Spanger-Siegfried 2004). The framework was based on four major principles, including that adaptation policy and measures should be in the context of development goals and not stand-alone, there should be a strong focus on vulnerability to current climate variability, and that stakeholders should be engaged throughout the planning and implementation processes. This is a framework that does not differ significantly from that of Carter et al. (1994), but it does articulate better the need to see adaptation in the wider context of societal goals (Table 1.2). But, as with Carter

\section{Table 1.2 Comparison of two influential frameworks for adaptation prepared a decade apart}

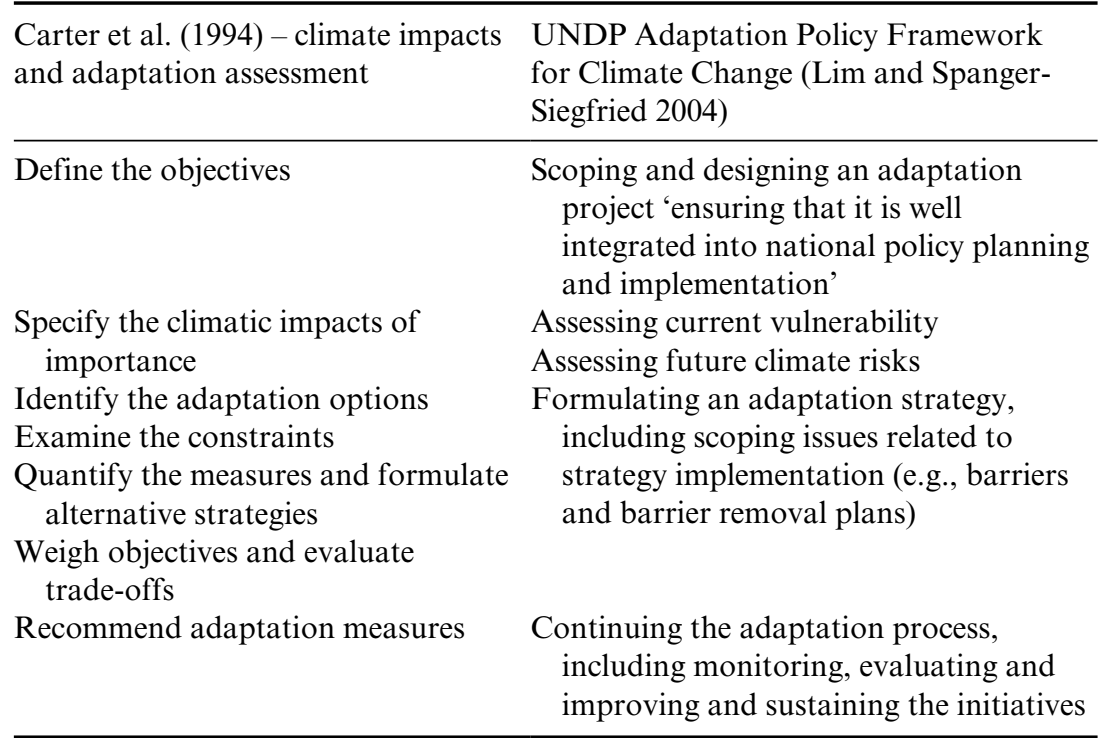


et al. (1994), adaptation strategies were still essentially initiated outside the core policy formulation process with the expectation that they would be mainstreamed into it and this would lead to implementation.

In 2005 the UNFCCC (2005) prepared a compendium of adaptation frameworks and approaches to assessing adaptation options. It recognised six complete frameworks including the two above, and another 50 or so tools for specific sectors. By 2014, Bours et al. in an analysis of frameworks specifically for monitoring and evaluation of adaptation projects identified 22 frameworks or similar documents. This proliferation of frameworks helped to progress the adaptation discourse, but most had little effect on practitioners, who preferred to stay with variants of betterknown frameworks such as the Adaptation Policy Framework.

\section{6-2010: WHO SHOULD PAY?}

\section{Adaptation as a Risk to Core Objectives}

Through the 2000s there were multiple estimates of the projected cost of mitigation actions, but few on the financial needs for adaptation. It was assumed that they would be considerably less than those for mitigation. The increasing discourse about adaptation led some development agencies to look more closely at the exposure of their own portfolios to climate risk. Analyses in the World Bank showed that approximately 40 per cent of projects were likely to have significant climate risks, but very few projects mentioned this risk in the design documents that went to the Board for approval. Rough estimates showed that if these risks had been identified and managed it would have added $\$ 1$ billion to $\$ 4$ billion per year to the overseas development assistance (ODA) and concessional finance portfolio (World Bank 2006). In 2006 the Stern report on The Economics of Climate Change was released (Stern 2007), and it built upon the World Bank analyses and estimated that in poor countries losses due to climate change could exceed 10 per cent of their gross domestic product (GDP). The Stern Review's results were contentious, and they stimulated a series of studies that used different assumptions of what constituted an adaptation cost and different methodologies (Parry et al. 2009; World Bank 2010). Most resulted in significantly higher cost estimates, but many objected to the attempts to monetize the social costs of losses and suffering caused by additional climate impacts. However, the net outcome of these studies was that it became clear that the costs of adapting were significant, and comparable with those for mitigation. The costs of not adapting would be even higher. 
The focus on costs gave added impetus to better integrating climate risk into development efforts and also to an ongoing discussion, mostly within the scholarly community, about fundamentally reframing our approach to adaptation (O'Brien 2006; Füssel and Klein 2006). The emphasis moved from a focus on identifying exposure and potential impacts, sometimes called an 'outcome' or 'end point' approach, to a better understanding of the social, economic, political and institutional factors that affect societies' underlying sensitivity to those impacts and their capacity to adapt - often called 'social vulnerability' or a contextual or a starting-point interpretation (Remling and Persson 2015). O'Brien (2006) argued for a 'human security' approach 'when and where individuals and communities have the options necessary to end, mitigate, or adapt to risks to their human, environmental, and social rights; have the capacity and freedom to exercise these options; and actively participate in attaining these options (GECHS, 1999)'.

At about this time development agencies and some regional governments and cities were moving to risk management approaches to adaptation (Willows and Connell 2003; CARICOM 2003; Asian Development Bank 2005; Rosenzweig et al. 2007). This was still essentially an impact assessment-driven approach; that is, assessing the risks, analysing how they can be managed and evaluating a strategy for doing so (Hellmuth et al. 2007; UNISDR 2005; Hammill and Tanner 2011), but with a more formally constructed response framed around risk management. This was a concept already familiar to many poverty reduction institutions, especially those involved in disaster management, and also to the private sector (Nyberg and Wright 2016). The risk management approach was particularly valuable in decision-making about resource allocation decisions, although this meant monetizing, or ignoring, many intangible losses and benefits.

\section{Integrating Adaptation into Disaster Risk Management and Development}

The Hyogo Framework for Action on disasters was agreed in 2005 (UNISDR 2005), and many countries and development agencies saw a value in closer cooperation, or merging, of their disaster risk management (DRM), adaptation and poverty reduction roles. These were often not convenient marriages (Mitchell et al. 2010), with differences in the scope of their remits (for example, DRM deals with a wider range of hazards), in terminology (for example, the meaning of the term 'mitigation'), differences in the dominant objectives (for example, rapid humanitarian response priorities versus proactive vulnerability reduction), and so on. But the cooperation has been productive in many ways. For example the Post-Disaster Needs Assessment (PDNA) for Fiji following Cyclone 
Winston in 2016 seeks to 'build back better' by taking into account a changing climate. The Red Cross/Red Crescent has developed 'Forecastbased Financing, which allows the release of funds where risks (e.g. drought) are considered to be high (for example, due to forecasted El Niño conditions) before crises develop. ${ }^{4}$ Small island states in the Caribbean and the Pacific are exploring innovative financial mechanisms such as liquidity insurance and contingent debt facilities that make funds available quickly for recovery, and for reconstruction more appropriate to future climates (Ghesquiere and Mahul 2010).

The IPCC AR4 (2007) report concluded that adaptation was occurring, but to a very limited extent, and rarely stand-alone but usually in response to an extreme event or embedded within a sectoral activity such as water planning. While the observations were valid, this report demonstrated the increasing disconnect between IPCC reporting and practice. Tighter rules about the IPCC's use of peer-reviewed publications and the paucity of reporting from many practitioners meant that about half of the citations in the IPCC adaptation chapter were published in 2003 or earlier, thus reflecting work that was five or more years old at the IPCC's release.

Meanwhile the IPCC received a request for a special report on Managing the Risks of Extreme Events and Disasters to Advance Climate Change Adaptation (SREX), which appeared in 2012, and which has had a far greater impact on the adaptation field, both scholarship and practice. Special Reports of the IPCC have a more tightly defined scope and often better-defined questions of relevance to policy formulation. SREX brought together several areas of scholarship and practice that had been somewhat separated, and was able to focus in more detail on specific questions. It sought to develop a common 'risk governance framework' that offered a more systematic way to situate judgements about disaster management, risk reduction and risk transfer. SREX also emphasized the need to consider the wider variety of cognitive, cultural and social processes that affect judgements about risk and about the allocation of efforts to address these risks (Loewenstein et al. 2001).

Development agencies were moving to integrate, or mainstream, climate risk into their poverty reduction activities. Mainstreaming places the emphasis on existing policies and measures rather than trying to insert adaptation-specific policies. The 'yet another thing to mainstream' response in many development agencies was moderated by an increasing acceptance of the significant risks that climate change represented to poverty reduction goals (Huq et al. 2004; McEvoy et al. 2008). The increasing emphasis on social vulnerability meshed better with existing thinking in the development policy community, but still a risk management approach dominated. 


\section{Developed-Country Adaptation Strategies and Performance}

The first National Adaptation Strategy (NAS) by a developed country (Finland) appeared in 2005 and provides an example of a developed country with a record of sound and well-resourced policy implementation (Finland 2005). The NAS began with a series of scenarios (climate, socioeconomic and natural systems), estimations of impacts and a 15-sector scoping of possible adaptation responses. It had a small section on the effects on Finland from climate risks in other parts of the world; it noted that a risk management approach may need to be applied more often in adaptation planning; and it included a very short section on communication to the community. Implementation was to be the responsibility of actors within the various sectors, noting that the current common planning cycles (5-10 years) may need to be lengthened.

In 2009 a cross-sectoral business panel (Finland 2009) evaluated progress against a five-point evaluation scale, on several fronts including the recognition of the need to adapt amongst stakeholders (from pioneers only, to widely recognized and accepted), the level of understanding of appropriate adaptation measures, and the extent to which implementation had progressed. The panel found that:

Finland, on average, is on step 2 in adaptation (on a scale from 1 to 5). This means that among the decision-makers there is at least some understanding of the impacts of climate change and the need for adaptation measures has been recognised, at least to a certain extent. (Finland 2009)

By the time of the next review (Finland 2013), progress was still limited:

The assessment shows that the action plan for adaptation aims primarily at mainstreaming adaptation into ordinary activities and objectives of the environmental administration. There are rather few measures aimed specifically at increasing adaptation to climate change. They also highlighted the need to improve monitoring mechanisms to assess the timeliness and sufficiency of policy measures.

European Union progress in adaptation planning in eight countries was reviewed by Biesbroek et al. (2010). They discussed the motivating and facilitating factors leading a country to produce an NAS. Motivating factors vary by country, but a recent extreme event was often cited, best facilitated by political will, good coordination between key actors across sectors and levels of government, and compatibility with other policies.

Bauer et al. (2012) found that by 2010, only ten out of the 34 OECD countries had an accessible adaptation strategy. After an analysis of the horizontal and vertical integration of adaptation policies in the 
wider policy framework they concluded that 'soft network mode[s] of governance (mainly characterized by mutual adaptation and persuasion)' predominated. As with other issues, such as sustainability, adequate governance approaches were essential, but not sufficient to overcome the numerous smaller barriers arising between policy formulation and implementation. Clar and Steurer (Chapter 15, this volume) discuss these issues further.

Within the research community the extent of transnational impacts of climate change on food security and health, and so on, was becoming clearer (e.g., Gregory et al. 2005). Few national strategies gave much consideration to the risks that might arise to supply or value chains from climate impacts upon trading partners, nor the impact on calls for assistance, increased migration or threats to security. An exception was the UK Government's (2011) Foresight Report that warned:

The top level message of this Report is that the consequences for the UK of climate change occurring in other parts of the world could be as important as climate change directly affecting these shores. The UK will inevitably be affected by these global impacts, and will need to give careful consideration to the implications for diplomacy and foreign policy, security, resources and commodities, finance and trade, human health and social values.

Here was a clear shift from the long-held mantra of 'mitigation is global while adaptation is local'.

\section{'New and Additional' Support for Adaptation}

In 2007 at CoP13 the Bali Action Plan introduced a series of major changes to the way adaptation was approached in the negotiations and beyond. The Plan called for significant resources to assist developing countries in both mitigation and adaptation, and that these funds should be "new and additional' to existing flows of support such as ODA. This led to intense discussions among developed and developing countries and NGOs about how adaptation funding should be sourced and assessed, and caused problems in development agencies of how to integrate adaptation into development while keeping financial flows separate. A preceding clause in the Bali Action Plan calling for 'adequate, predictable and sustainable financial resources' identified an equally or more important need, but it did not have the impact of the call for new and additional resources.

$\mathrm{CoP} 13$ also agreed to the formation of the Adaptation Fund, which was to draw upon resources from a tax on the Clean Development Mechanism (CDM) agreed to in Kyoto in 1997. Developing countries felt strong ownership of this Fund and encouraged its Board to consider 'direct access' by 
recipient countries to its funds; that is, developing country governments could design, be funded and manage projects without the necessity of working through one of the major development agencies (see Persson and Atteridge, Chapter 18 in this volume). Direct access was consistent with a trend amongst development banks away from funding specific projects, to agreeing with recipient countries on a series of objectives and measureable milestones in achieving them, and then providing direct budgetary support for the government to manage this through their normal institutions and procedures. Direct access and budgetary support meant that measuring whether funding from climate change actions was new and additional became increasingly problematic. Together, these points strengthened the position of adaptation in the negotiations and strongly influenced practice among development agencies. But they also raised concerns among some of the strongest financial supporters of adaptation funding who would have to report to their parliaments and electorates on the use of those funds.

McGray et al. (2007) provided a useful insight by describing a continuum between narrowly defined adaptation activities aimed specifically at addressing impacts of climate change, to more traditional development activities of building response capacity and addressing the drivers of vulnerability. Development agencies and potential contributors (donors) committed to increased funding flows through what was to become the Green Climate Fund felt that there was a need to explore ways to more effectively mainstream, or integrate, climate risk and resilience into core development planning. They launched the Pilot Program for Climate Resilience (PPCR) to pilot country-led programmes of significant scale (World Bank 2015). The pilot countries were to receive approximately $\$ 100$ million each for a small number of significant-sized projects: that is, projects that would match, or exceed, funding that might be received initially through the new Funds for adaptation. One of the main effects of the PPCR was to encourage recipient countries to rethink institutional structures and the decision-making framework for integrating climate risks into their governance structures.

\section{POST-2010: 'JUST GET ON WITH IT'}

The confusion over how to interpret the Bali Action Plan; the failure of CoP15 in Copenhagen (2009) to achieve its ambitions; the increased flow of finance for adaptation through the 'Fast Track' process (Cancun CoP16) and the encouragement for developing countries to produce National Adaptation Plans (NAPs); Green Climate Funds coming on 
line; and the paucity of actionable advice from IPCC AR5, led many development agencies to decide to simply get on with integrating climate resilience into their day-by-day work. By selecting 'Climate Change and Development' as the topic for its 2010 World Development Report, the World Bank signalled the importance of the relationship to its core tasks; recipient countries increased their interest in integrating adaptation into the country assistance plans that guided development support, and many were already directing significant national resources towards adaptation.

In 2013, with the replenishment of the World Bank's IDA17, which offers grants and highly concessional loans to the poorest developing countries, it was agreed that all proposals were to be screened for climate risks and must integrate appropriate resilience measures (World Bank 2013). Based on PPCR experience, this could add about 25-30 per cent to the costs of development in the c. $\$ 17$ billion per year of support to leastdeveloped countries. Unless special arrangements are made with donors this will be borne largely as an additional cost to achieving development.

The World Bank also produced core research on the impacts of climate change on poverty, showing that unmitigated climate change and inadequate adaptation measures will push increasing numbers of people back into poverty (Hallegatte et al. 2015), further establishing the threat of climate change to global development goals. Although there will always be a demand for further funding, in most developing countries it is not funds that limit progress on adaptation. The social costs and consequences of changing livelihoods, of relocating homes and losing cultural assets, often override the best plans for increasing resilience. Also, progress is thwarted by lack of capacity: not a lack of skill, but simply the lack of enough people with those skills, and stable and rewarding positions in their country to let them apply them. Both limitations were foreseen over a decade ago in a policy note on the Pacific Islands region, Not If, But When (Bettencourt et al. 2006).

At this time some warned of the risks of maladaptation: that is, actions or inaction that may lead to increased risk of adverse climate-related outcomes, increased vulnerability to climate change, or diminished welfare, now or in the future. This issue has been much debated and various frameworks for avoiding possible maladaptation have been proposed (Barnett and O'Neill 2010; Magnan 2014). While potentially maladaptive actions should be avoided wherever possible, there are going to be cases where the action preferred from an adaptation viewpoint may not be the action selected after taking into account a wider range of societal preferences (Noble et al. 2014). Hallegatte's (2009) framework for identifying robust adaptation options is a more useful guide to practice in these cases. 


\section{RESTORING THE BALANCE}

If current trends continue, adaptation in developed countries will increasingly be addressed at sub-national levels and especially in cities and local government, preferably with the cooperation of the national government or in some countries, despite it. Within developing countries responsibility for adaptation is moving from environmentally oriented agencies, which have dominated until recently, to more senior agencies responsible for finance or planning. Increasingly climate is seen as another risk or volatility that needs to be managed and funded while development objectives are pursued. But agencies dealing with adaptation in small developing countries are often overstretched in attempting to respond to differing requirements of adaptation funding agencies, multiple planning and reporting challenges (for example, National Adaptation Plans, Nationally Determined Contributions - NDCs, consistency with Sustainable Development Goals), and shifting conceptualizations of adaptation (for example, the Green Climate Fund's focus on 'transformative' change). There is also wide support for developing countries to take more direct responsibility for adaptation planning and implementation through Direct Access Mechanisms (for example, the Adaptation Fund and Green Climate Fund) and budget support mechanisms by development banks to support the integration of climate resilience into development planning and implementation. On top of these demands many small countries have a legacy of multiple small adaptation projects already under way, each demanding resources and skills. It is essential that in preparing their NAPs each developing country reassesses its institutional structure and national priorities.

As the funding for adaptation increases, the need to assess which actions achieve the best outcomes, and the need for consistent reporting of adaptation outcomes via transparent and repeatable metrics, are becoming more important (Eriksen and Kelly 2007; Lesnikowski et al. 2015; UNEP 2014, 2017). Here we must seek the best available approaches rather than seeking to match the same standards as for mitigation. This is becoming more urgent, lest adaptation is again sidelined as too difficult to monitor effectively.

Adaptation will likely remain the neglected twin within the negotiations; not by deliberate neglect, but because of the immediate demands of the noisier mitigation sibling. This was apparent at the Paris CoP21 (2015). Mitigation clearly had to be the dominant issue and NDCs will remain the core element of negotiations. But it is proving difficult to apply that same model to adaptation. It is difficult to measure adaptation efforts: both inputs and, especially, outcomes. Even if we were to make more progress in doing this, mitigation and adaptation 'contributions' are not fungible. 
Within the negotiations, losses and damages associated with the adverse effects of climate change that exceed what can be reduced by adaptation loomed large in the Warsaw CoP of 2013 and with it the pressure to acknowledge culpability and the case for compensation. Some think that loss and damage will become a third paradigm, along with mitigation and adaptation, in the climate change regime (Warner and Zakieldeen 2012; Vanhala and Hestbaek 2016). Some developed countries appear to be seeking to frame this debate around insurance, thereby minimizing questions of culpability, but also ignoring the many consequences that fall outside of insurable risk. The outcome of the loss and damage debate remains unclear but it is likely to have huge effects, positive and negative, on supporting the most vulnerable. Unfortunately, there appears to be little opportunity within the negotiations to address the inequality or unequal power structures that underlie people's vulnerability. Maybe the threat of loss and damage will bring some further positive decisions in future CoPs, but, to many, the status quo of CoPs offering some additional funds for adaptation and further sharing of experiences is still acceptable.

Scholastically the literature is doubling every five years (IPCC AR5 WGII Chpt 1) and the number of papers published on adaptation is now in the thousands per year; unfortunately committing most of them to be literature chaff rather than nurturing grain. Stronger themes are emerging in relation to barriers to effective action, equity issues and maybe even liability. These important themes and ideas are for the rest of this volume.

A major driver of change is the increasing engagement of social sciences and the move away from a focus on impacts and proximate causes of vulnerability to more of a focus on such issues as societal relationships to place, and the need for the evolution of existing institutions (Wise et al. 2014; Adamson et al. 2018). This will require learning and relearning on both sides, which this volume seeks to contribute to.

We have mostly completed the transition from adaptation being achieved through the 'invisible hand' to the recognition that we need proactive adaptation. Some progress has been made on sharing the responsibility for adaptation action. The question is now how best to achieve effective adaptation. To reiterate this book's goals, it is to seek to explain not what is, or is not, happening in adaptation, but why. And here there is already a deep resource of scholarship in governance and development to draw upon.

This raises the question as to whether the IPCC is the place for the further development of adaptation thought and communication between scholars, negotiators and practitioners. The IPCC was conceived of as a process for reporting recent advances in our understanding of climate 
change and its impacts largely in biophysical terms, rather than to explore, debate and develop a wider and more effective conceptual bases for progress. Its current rules and mode of operation mean that its assessments of adaptation come too late, are too long and too conceptual to engage either the negotiators or the practitioners. Maybe dialogues between the actors can lead to well-conceived IPCC special reports. Or maybe a different structure is needed. Scholarship will continue. The risk is that there will be a further drifting apart of scholarship and practice, which will be bad for both. But the practitioners have enough to do. It will be for the scholars to ensure that the drift is contained.

\section{NOTES}

1. For the origins of the term 'greenhouse effect' see Easterbrook (2015).

2. Throughout this chapter I use a standardized abbreviation for the IPCC Assessment Reports as IPCC AR1, IPCC AR2, and so on; and to the Working Groups as WGII, and so on. The full texts of all the IPCC Assessment Reports and Special Reports are available at https://www.ipcc.ch/publications_and_data/publications_and_data_reports. shtml.

3. Even as late as AR3 (2001) a more defensive definition was still being used for no-regret policies, that is, those 'that would generate net social benefits whether or not there is climate change'. This largely derived from its use in mitigation, where proponents of action still met strong resistance both from those uncertain about the climate change phenomenon, and from those anticipating the high costs of action. The term 'win-win' was interpreted in at least two ways: as in no-regrets because the activity would be beneficial whether specific impacts occurred or not; or because there would be multiple benefits, one of which would be to increase climate resilience. Others have adopted a more nuanced use of 'no-regrets' to refer to activities that are expected to be robust in the face of uncertainty about the nature and timing of climate changes (e.g., Kissinger and Namgyel 2013). This is similar to the concept of 'robust adaptation' (Lempert et al. 2004; Dessai \& van der Slujis 2007).

4. http://www.climatecentre.org/programmes-engagement/forecast-based-financing accessed 9 March 2018.

\section{REFERENCES}

Adamson, G.C.D., Hannaford, M.J., and Rohland, E.J. (2018). Re-thinking the present: the role of a historical focus in climate change adaptation research. Global Environmental Change, 48, 195-205.

Allan, J., Bhandary, R.R., Bisiaux, A., Chasek, P., Jones, N., Luomi, M., .. Woods, B. (eds) (2017). From Bali to Marrakech: a decade of international climate negotiations as told by the Earth Negotiations Bulletin. Winnipeg, Canada: IISD. https://www.iisd.org/.../ bali-marrakech-decade-international-climate-negotiations.pdf

Arrhenius, S. (1908). Worlds in the making: the evolution of the universe. New York, USA and London, UK: Harpers Bros.

Asian Development Bank (2005). Climate proofing: a risk based approach to climate change. Asian Development Bank. 
Barnett, J., and O'Neill, S. (2010). Maladaptation. Global Environmental Change: Human and Policy Dimensions, 20, 211-213.

Bauer, A., Feichtinger, J., and Steurer, R. (2012). The governance of climate change adaptation in 10 OECD countries: challenges and approaches. Journal of Environmental Policy and Planning, 14, 279-304.

Bettencourt, S., Croad, R., Freeman, P., Hay, J., Jones, R., King P., ... Van Aalst, M. (2006). Not if but when: adapting to natural hazards in the Pacific Islands region. Washington, DC: World Bank.

Biesbroek, G.R., Swart, R.J., Carter, T.R., Cowan, C., Henrichs, T., Mela, H., . . Rey, D. (2010). Europe adapts to climate change: comparing national adaptation strategies. Global Environmental Change, 20, 440-450.

Bodansky, B. (1993). The United Nations Framework Convention on Climate Change: a commentary. Yale Journal of International Law, 18(2), 451-558.

Bours, D., McGinn, C., and Pringle, P. (2014). Monitoring and evaluation for climate change adaptation and resilience: a synthesis of tools, frameworks and approaches (2nd edn). Phnom Penh: SEA Change CoP; Oxford: UKCIP.

Burton, I. (1996). The growth of adaptation capacity: practice and policy. In J.B. Smith, N. Bhatti, G.V. Menzhulin, R. Benioff, M. Campos, B. Jallow, ... R.K. Dixon (eds), Adapting to Climate Change (pp.55-67). New York: Springer Verlag.

Burton, I. (1997). Vulnerability and adaptive response in the context of climate and climate change. Climatic Change, 36, 185-196.

Burton, I., Huq, S., Lim, B., Pilifosova, O., and Schipper, E.L. (2002). From impacts assessment to adaptation priorities: the shaping of adaptation policy. Climate Policy, 2, $145-159$.

Burton, I., and van Aalst, M. (1999). Come hell or high water: integrating climate change vulnerability and adaptation into bank work. Environment Department papers No. 72. Washington, DC: World Bank.

CARICOM (2003). Adapting to Climate Change in the Caribbean (ACCC) project. Caribbean risk management guidelines for climate change adaptation decision making. Caribbean Community Secretariat.

Carter, T.R., Parry, M.L., Harasawa, H., and Nishioka, S. (eds) (1994). IPCC technical guidelines for assessing climate change impacts and adaptations. Department of Geography, University College, London.

Darwin, R., Tsigas, M., Lewandrowski, J., and Raneses, A. (1995). World agriculture and climate change: economic adaptations. Agricultural Economic Report No. 703. USDA.

Dessai, S., and van der Sluijs, J. (2007). Uncertainty and climate change adaptation: a scoping study. Copenhagen: Copernicus Institute.

Easterbrook, S. (2015). Who first coined the term 'greenhouse effect'? Serendipity Blog. http://www.easterbrook.ca/steve/2015/08/who-first-coined-the-term-greenhouse-effect/ (accessed November 2017).

Ehrlich, P.R. (1968). The population bomb. New York: Ballantine Books.

Eriksen, S.H., and Kelly, P.M. (2007). Developing credible vulnerability indicators for climate adaptation policy assessment. Mitigation and Adaptation Strategies for Global Change, 12, 495-524.

Fiji, Government (2016). Post disaster needs assessments. Cyclone: Tropical Cyclone Winston. February 20.

Finland, Government (2005). Finland's National Strategy for Adaptation to Climate Change. Ministry of Agriculture and Forestry, Publ. 1a/2005.

Finland, Government (2009). Implementation of Finland's National Strategy for Adaptation to Climate Change 2009. Ministry of Agriculture and Forestry, Publ. 4a/2009.

Finland, Government (2013). Assessment of the Environmental Administration's Action Plan for Adaptation to Climate Change. Ministry of the Environment 3/2013. (In Finnish, English summary.)

Füssel, H.-M., and Klein, R.J.T. (2006). Climate change vulnerability assessments: evolution of conceptual thinking. Climatic Change, 75, 301-329. 
Future Earth (2013). Future Earth initial design: report of the transition team. Paris: International Council for Science (ICSU).

GECHS (1999). Global environmental change and human security. GECHS Science Plan. Bonn: IHDP.

Ghesquiere, F., and Mahul, O. (2010). Financial protection of the state against natural disasters: a primer. Policy Research Working Paper 5429. Washington, DC: World Bank.

Glantz, M.H. (1977). Nine fallacies of natural disaster: the case of the Sahel. Climatic Change, 1, 69-84.

Gore, C. (2000). The rise and fall of the Washington Consensus as a paradigm for developing countries. World Development, 28, 789-804.

Gregory, P.J., Ingram, J.S.I., and Brklacich, M. (2005). Climate change and food security. Philosophical Transactions of the Royal Society, Series B, 360, 2139-2148.

Hallegatte, S. (2009). Strategies to adapt to an uncertain climate change. Global Environmental Change, Human and Policy Dimensions, 19, 240-247.

Hallegatte, S., Bangalore, M., Bonzanigo, L., Fay, M., Kane, T., Narloch, U., ... VogtSchilb, A. (2015). Shock waves managing the impacts of climate change on poverty. Climate Change and Development Series. Washington, DC: World Bank.

Hammill, A., and Tanner, T. (2011). Harmonising climate risk management: adaptation screening and assessment tools for development co-operation. OECD Environment Working Papers, No. 36. OECD Publishing.

Hardin, G. (1968). The tragedy of the commons. Science, 162, 1243-1248.

Hellmuth, M.E., Moorhead, A., Thomson, M.C., and Williams, J. (eds) (2007). Climate risk management in Africa: learning from practice. New York: International Research Institute for Climate and Society (IRI), Columbia University.

Huq, S., Reid, H., Konate, M., Rahman, A., Sokona, Y., and Crick, F. (2004). Mainstreaming adaptation to climate change in least developed countries (LDCs). Climate Policy, 4, 25-43.

Kates, R.W. (1997). Climate change 1995: impacts, adaptation and mitigation. A review. Environment, 39(9), 29-33.

Kates, R.W. (2000). Cautionary tales: adaptation and the global poor. Climatic Change, 45, $5-17$.

Keeling, D. (1960). The concentration and isotopic abundances of carbon dioxide in the atmosphere. Tellus, 12, 200-203.

Kissinger, G., and Namgyel, T. (2013). NAPAs and NAPs in least developed countries. LDC Paper Series. ecbi Publications.

Klein, R.J.T., Eriksen, S.E.H., Næss, L.O., Hammill, A., Tanner, T.M., Robledo, C., and O'Brien, K.L. (2007). Portfolio screening to support the mainstreaming of adaptation to climate change into development assistance. Climatic Change, 84, 23-44.

Landsberg, H.E. (1970). Man-made climatic changes. Science, 170, 1265-1274.

Lempert, R., Nakicenovic, N., Sarewitz, D., and Schlesinger, M. (2004). Characterizing climate-change uncertainties for decision makers: an editorial essay. Climatic Change, 65, $1-9$.

Lesnikowski, A.C., Ford, J.D., Berrang-Ford, L., Barerra, M., and Heyman, J. (2015). How are we adapting to climate change? A global assessment. Mitigation and Adaptation Strategies for Global Change, 20, 277-293.

Lim, B., and Spanger-Siegfried, E. (eds) (2004). Adaptation policy frameworks for climate change - developing strategies, policies and measures. New York: UNDP and Cambridge University Press.

Loewenstein, G.F., Weber, E.U., Hsee, C.K., and Welch, E. (2001). Risk as feelings. Psychological Bulletin, 127, 267-286.

Magnan, A. (2014). Avoiding maladaptation to climate change: towards guiding principles. SAPIENS, 7(1), 1-11.

Manabe, S., and Wetherald, R.T. (1967). Thermal equilibrium of the atmosphere with a given distribution of relative humidity. Journal of Atmospheric Sciences, 24, 242-259.

McEvoy, D., Lonsdale, K., and Matczak, P. (2008). Adaptation and mainstreaming of EU 
climate change policy: an actor-based perspective. Centre for European Policy Studies, No. 149.

McGray, H., Hammill, A., Bradley, R., Schipper, E.L., and Parry, J.-E. (2007). Weathering the storm: options for framing adaptation and development. Washington, DC: WRI.

Mitchell, T., van Aalst, M., and Villanueva, P.S. (2010). Assessing progress on integrating disaster risk reduction and climate change adaptation in development processes. SCR Discussion Paper 2. DFID UK.

Morais, J. (2015). A personal note on the IGBP and the social sciences. http://www.igbp. net/news/features/features/apersonalnoteonigbpandthesocialsciences.5.950c2fa1495db70 81e18757.html

Noble, I.R., Huq, S., Anokhin, Y.A., Carmin, J., Goudou, D., Lansigan, F.P., ... Villamizar, A. (2014). Adaptation needs and options. In IPCC, AR5, WGII Impacts, Adaptation, and Vulnerability (pp. 833-868). Cambridge, UK and New York, USA: Cambridge University Press.

Nyberg, D., and Wright, C. (2016). Performative and political: corporate constructions of climate change risk. Organization, 23, 617-638.

O'Brien, K. (2006). Are we missing the point? Global environmental change as an issue of human security. Global Environmental Change, 16, 1-3.

Oppenheimer, M. (2007). How the IPCC got started. Blog. http://blogs.edf.org/climat e411/2007/11/01/ipcc_beginnings/ (accessed 9 March 2018).

Orlove, B. (2009). The past, the present and some possible futures of adaptation. In W.N. Adger, I. Lorenzoni, and K. O'Brien (eds), Adapting to climate change: thresholds, values, governance (pp. 131-163). Cambridge: Cambridge University Press.

Oxfam (1983). Weather alert: extreme weather and the world's poor. Oxford: Oxfam.

Oxfam (2000). Climate change: the implications for Oxfam's programme, policies and advocacy. Oxford: Oxfam.

Parry, M., Arnell, N., Berry, P., Dodman, D., Fankhauser, S., Hope, C., ... Wheeler, T. (2009). Assessing the costs of adaptation to climate change: a review of the UNFCCC and other recent estimates. London: International Institute for Environment and Development and Grantham Institute for Climate Change.

Phillips, N.A. (1956). The general circulation of the atmosphere: a numerical experiment. Quarterly Journal of the Royal Meteorological Society, 82, 123-154.

Pielke Jr, R.A. (1998). Rethinking the role of adaptation in climate policy. Global Environmental Change, 8(2), 159-170.

Plass, G.N. (1956). The carbon dioxide theory of climate change. Tellus, 8, 140-154.

PSAC (1965). Restoring the quality of our environment. Washington, DC: US Government Printing Office.

Remling, E., and Persson, Å. (2015). Who is adaptation for? Vulnerability and adaptation benefits in proposals approved by the UNFCCC Adaptation Fund. Climate and Development, 7, 16-34.

Rosenzweig, C., Major, D.C., Demong, K., Stanton, C., Horton, R., and Stults M. (2007). Managing climate change risks in New York City's water system: assessment and adaptation planning. Mitigation and Adaptation Strategies for Global Change, 12, 1391-1409.

Rosenzweig, C., and Parry, M. (1994). Potential impact of climate change on world food supply. Nature, 367, 133-138.

Schipper, E.L.F. (2006). Conceptual history of adaptation in the UNFCCC process. RECIEL, 15(1), 82-92.

Seitzinger, S.P., Gaffney, O., Brasseur, G., Broadgate, W., Ciais, W., Claussen, M., ... Uematsu, M. (2015). International Geosphere-Biosphere Programme and Earth system science: three decades of co-evolution. Anthropocene, 12, 3-16.

Smith, J.B., Bhatti, N., Menzhulin, G.V., Benioff, R., Campos, M., Jallow, B., ... Dixon, R.K. (eds) (1996). Adapting to climate change. New York: Springer Verlag.

Smith, J.B., and Tirpak, D. (1989). The potential effects of global climate change on the United States. EPA-230-05-89-050, Washington, DC. 
Stern, N.H. (2007). The economics of climate change: the Stern review. Cambridge: Cambridge University Press.

UKCIP (2011). Making progress: UKCIP and adaptation in the UK. Oxford: UK Climate Impacts Programme.

UK Government (2011). Foresight international dimensions of climate change. London: Government Office for Science.

UNEP (2014). The adaptation gap report 2014. Nairobi: United Nations Environment Programme.

UNEP (2017). The adaptation gap report 2017. Nairobi: United Nations Environment Programme.

United Nations (UN) (1972). Report on the UN Conference on Human Environment. Switzerland and Nairobi.

UNFCCC (1992). United Nations Framework Convention on Climate Change. Bonn: UNFCCC Secretariat.

UNFCCC (2005). Compendium on methods and tools to evaluate impacts of, and vulnerability and adaptation to, climate change. Bonn: UNFCCC Secretariat.

UNISDR (2005). Hyogo Framework for Action 2005-2015: building the resilience of nations and communities to disasters. Geneva: UNISDR.

United Nations (UN) (1987). Our common future: Brundtland report. Oxford, UK and New York, USA: Oxford University Press.

United Nations (UN) (1998). Kyoto Protocol to the United Nations Framework Convention on Climate Change. New York: United Nations.

USA National Assessment Synthesis Team (2000). Climate change impacts on the United States: the potential consequences of climate variability and change. Washington, DC: US Global Change Research Program.

Vanhala, L., and Hestbaek, C. (2016). Framing climate change loss and damage in UNFCCC negotiations. Global Environmental Politics, 16, 111-129.

Vergara, W. (2005). Adapting to climate change lessons learned, work in progress, and proposed next steps for the World Bank in Latin America. LAC Sustainable Development Working Paper No. 25.

Warner, K., and Zakieldeen, S.A. (2012). Loss and damage due to climate change: an overview of the UNFCCC negotiations. Oxford: European Capacity Building Initiative.

Willows, R.I., and Connell, R.K. (eds) (2003). Climate adaptation: risk, uncertainty and decision-making. UKCIP Technical Report. Oxford: UKCIP.

Wise, R.M., Fazey, I., Stafford Smith, M., Park, S.E, Eakin, H.C., Archer van Garderen, E.R.M., and Campbell, B. (2014). Reconceptualising adaptation to climate change as part of pathways of change and reponse. Global Environmental Change, 28, 326-336.

World Bank (2005). World Bank Group historical chronology. http://siteresources.worldbank. org/EXTARCHIVES/Resources/WB_Historical_Chronology_1944_2005.pdf (accessed November 2017).

World Bank (2006). Clean energy and development: towards an investment framework, Annex K.

World Bank (2010). The economics of adaptation. Washington, DC: World Bank.

World Bank (2013). Special themes for IDA17: IDA Resource Mobilization Department concessional finance and global partnerships. Washington, DC: World Bank.

World Bank (2015). Key lessons from the Pilot Program for Climate Resilience. WB Climate Guidance Note. Washington, DC: World Bank. 